\title{
DISCLAIMER
}

This report was prepared as an account of work spensored by an agency of the United States Government. Neither the United States Government nor any agency thereof. nor any of their employees, makes any warranty, express or implied, or assumes any legal livbility ir responsibility for ate accuracy, completeness, or usefulness of any information, apparalus. product, or process disctosed, or represents that its use would not infringe privately owned rights. Reference herein to any specific commercial product, ptocess, or scrvice by trade nains, trademark, manufacturer, of otherwise does not ocecsearily conseitute of imply its endorsernenc, tecommendation, or favoring by the Uaiter States Government or any agency thereuf. The views and opinions of authors expressed herein do not necessarily slate or reflecl those of the United States Government or ary agency thereor.

\section{EROSION AND REDEPOSITION EXPERIMENTS IN THE PISCES FACILITY}

D.M. Goebel, Y. Hirooka, R.W. Conn, W.K. Leung, G.A. Campbell, J. Bohdansky, ${ }^{1}$ K.L. Wilson, 2 W.Bauer, ${ }^{2}$ R.A. Causey, ${ }^{2}$ A.E. Pontau, ${ }^{2}$ A.R. Krauss, ${ }^{3}$ D.M. Gruen, ${ }^{3}$ M.H. Mendelsohn ${ }^{3}$

School of Engineering and Applied Science Center for Fusion Physics and Engineering University of Califonia, Los Angeles, CA 90024

1 - Max-Plank-Institut fur Plasmaphysik. Garching, Fed. Rep. Germany

2 - Sandia National Laboratory, Livermore, Califorsia, USA

3 - Argonne National Laboratory, Argonne, Illinois, USA 


\section{InPAT,}

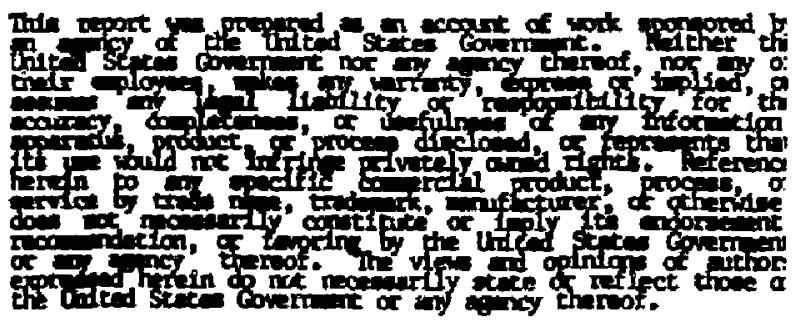




\section{EROSION AND REDEPOSITION EXPERIMENTS IN THE PISCES FACILITY}

D.M. Goebel, Y. Hirooka, R.W. Conn, W.K. Leung, G.A. Campbell

Center for Fusion Physics and Engineering

University of California, Los Angeles

Los Angeles, CA 90024, U.S.A.

J. Bohdansky

Max-Plank-Institut fur Plasmaphysik, Garching, Fed. Rep. Germany

K.L. Wilson, W.Baver, R.A. Causey, A.E. Pontau

Sandia National Laboratory, Livermore, Califomia, USA

A.R. Krauss, D.M. Gruen, M.H. Mendelsohn

Argonne National Laboratory, Argonne, Illinois, USA

Key words: erosion, redeposition, sputtering yields, chemical sputtering of carbon

The modfication of surfaces during exposure to plasma bombardment is a critical issue in the development of limiter and wall materials for fusion confinement experiments. Controlled studies of the erosion and redeposition of materials during high flux and fluence plasma exposure are now possible in the PISCES facility. PISCES is a continuously operating plasma device which has achieved hydrogen plasma densities of over $10^{13} \mathrm{~cm}^{-3}$ and electron temperatures of 5 to $24 \mathrm{eV}$ over large areas. Ion fluxes of $10^{17}$ to $10^{19} \mathrm{~cm}^{-2} \mathrm{sec}^{-1}$ and fluences of up to $10^{23} \mathrm{~cm}^{-2}$ have been used to bombard biased samples inserted into the plasma. The plasma parameters can be selected to produce simple sputtering, or redeposition by the ionization and recycling of the sputlered target materials. Collaborative studies on the performance of $\mathrm{Cu}$ and $\mathrm{Cu}-\mathrm{Li}$ alloys (with ANL), stainless steel (with SNL), and graphite (with IPP at Garching, and SNLL) have been undertaken. Surface topography modification is always observed after a sufficient fluence is achieved. The net erosion rate is significantly lower during redeposition than one would expect from classical sputtering yields. The transpon and deposition of different materials by the plasma to the samples during redeposition conditions results in greatly modified surface composition dind morphology. Clemical sputtering of graphite during low energy, high flux $\left(>10^{18} \mathrm{~cm}^{-2} \mathrm{sec}^{-1}\right)$ plasma bombardment is observed. Chemically formed hydrocarbons are relatively easily redeposited compared to sputtered carbon. The performance of these materials, the surface morphology evolution, and the characteristics of the redeposited materials are discussed. 


\section{Introduction}

Investigations of plasma-materials interactions (PMI) relevant to fusion research have generally been performed in major plasma confinement devices or laboratory ion beam facilities. In tokamaiks, collection probes have been used $(1,2)$ to measure the impurty fluxes in the scrapeoff layer (SOL) plasma. Limiter components(3-11) and samples placed on or near the walls have been analyzed after extended exposure to plasma discharges. This provides data on the erosion and redistribution of the materials in the tokamak. Ion beam facilities produce basic data on the sputtering of materials. $(12,13)$ The erosion of materials as a function of the ion energy and mass is obtained. However, the PMI data base extracted from these entirely different techniques is not yet adequate 10 predict the performance or complete the development of in-vessel materjals and components for future machines.

In confinement machines, comprehensive studies of materials performance are complicated by the varied experimental programs and the transport and mixing of the different materials in the device by the plasma. The exposure history of the materials, the role of disruptions, and the effect of the start-up and ending phases of the pulses make interpertation of the results difficult. Alternately, ion beams cannot produce high current densities and plasma effects sucil as ionization and redeposition of the sputtered materials which are crucial to understanding materials performance in fusion experiments. PISCES $(14,15)$ represents a significant step upwards from ion beam laboratory facilities in the simulation of PMI in major confinement machines.

The PISCES facility utilizes a continuously operating magnetized plasma to bombard biased samples. The degree of plasma interaction with the target material can be selected by choosing the density and temperature of the plasma. At low electron temperatures, high rate sputtering of the surface occurs. Alternatively, a combination of high density and electron temperature can be selected to produce ionization of the sputtered material. The confining magnetic field and potential distribution in the plasma guide the fonized sample materials, and any other materials 
introduced into the plasma, to the sample surface. Erosion, redeposition and mixing of materials characteristic of PMI in confinement devices can therefore be studied in controlled experiments.

in this paper, wel present the results of some recent experiments on several materials of interest for fusion applications. The erosion and redeposition of copper, intended for high heat flux applicatious, has been examined. Tests have been made of the performance during plasma bombardment of a low $\mathrm{Z}$ protective layer on $\mathrm{Cu}$, achieved by a segregated $\mathrm{Li}$ layer, in collaboration with ANL. The modification of the surface structure and composition of stainless steel during redeposition will be discussed. This has implications for tritium permeation in the vacuum vessels of confinement machines. Finally, several aspects of the performance of graphite have been investigated in PISCES in collaboration with IPP, Garching, and with SNLL. Specifically, the low energy sputtering yeild by physical and chemical processes, surface morphology evolution, and the redeposition of hydrocarbons, will be discussed.

\section{Experimental Arrangement}

The experimental layout of PISCES is shown in Fig. 1. The device consists of a high current densiry, continuously operating plasma generator coupled to a $2 \mathrm{~m}$ long and $20 \mathrm{~cm}$ diameter, water-cooled, stainless steel vacuum system. Turbomolecular pumps, with a total pumping speed of about $4000 \mathrm{l} / \mathrm{sec}$, produce a base pressure prior to operation of $1 \times 10^{-7}$ torr. Differential pumping between the plasma generator and target region is used to reduce the background pressure during experiments. The pressure is determined by the gas type and desired plasma conditions, and typically ranges from 1 to $10 \times 10^{-4}$ torr. The plasma is produced by a continuously operating discharge from a lanthanum hexaboride electron emitter(16) to a cylindrical anode. Discharge currents of up to $600 \mathrm{~A}$ at $100 \mathrm{eV}$ are used to generate the plasma. Plasmas of $\mathrm{H}, \mathrm{D}, \mathrm{He}, \mathrm{N}$, and Ar have been obtained. An axial magnetic field of 0.2-1 kgauss from solenoid coils is used to confine and guide the plasma from the generation region to the sampie location. 
The plasma density and potential peak in the plasma generator region. Ions produced on either side axially of the potential peak flow to the target region or cathode respectively. Flasma generator impurities, such as La and B from the cathode, are trapped in the plasma generator and only observed in the larget region during low density, cold plasma operation when the impurity ionization mean-free-path is long. Likewise, materials jonized in the column tend to return to the sample and redeposit or self-sputter the surface. Because the ions escape freely along the axial magnetic field to the ends of the machine, the ion energy is low and the bombarding energy is determined primarily by the applied bias on the target. The energy gained by the primary ions from the plasma potential difference between the generator region and target is determined by probes and accounted for in the ion energy measurements. Energy anajysis of the ions by a retarding grid energy analyzer produces similar results as deduced from the probe measurements and the sample bias.

In PISCES, plasma densities of $10^{11}$ to $10^{13} \mathrm{~cm}^{-3}$ and electron temperatures of 5 to $24 \mathrm{eV}$ are available (Fig.2). The parameters are selected by adjusting the neutral gas feed rate and the discharge power. Ionization percentages of $50 \%$ for hydrogen plasmas and over $90 \%$ for argon plasmas, are achievable depending on the conditions selected. Target fluxes of over $1 \mathrm{~A} / \mathrm{cm}^{2}$ of the above mentioned gases, or combinations of them, are produced over an area of 50 to $80 \mathrm{~cm}^{2}$. PISCES parameters are summarized in Table 1.

Diagnostics for PISCES, also shown in Fig.l, are complicated by the relatively high plasma power levels and the continuous operation. All parts inserted into the vacuum vessel must be cooled, or moved in and out quickly. Shielded ionization gauges, a residual gas analyzer, and a low pressure baratron are used to monitor the vacuum conditions. The plasma parameters are measured by scanning Langmuir probes and a microwave interferometer. Miniature water-cooled flat probes and a fast moving probe have been developed. Impurities in the plasma, including sputtered materials, are detected by a spectrometer and optical multichannel analyzer (OMA) system. The sputtering of the samples and the plasma dump results in coating of the windows in a relatively short time during continuous operation, and fast shutters have been installed to protect 
the windows. The short exposure time to the plasma of the optical components and the fast probes dictate that the data acquisition system operate in a pulsed mode.

The materials to be tested are inserted from the end of the machine to the exposure region through a vacuum interlock. Depending on the sample cooling time, it is possible to exchange samples in less than 5 minutes without breaking the vacuum in PISCES. Cooling of the samples is achieved by clamping to the biasable manipulator by a screw-cap arrangement. Samples of $2.5 \mathrm{~cm}$ in diameter are typically used, with the size determined primarily by the surface analysis station capabilities. A water cooled copper manipulator is used for low temperature samples, and an air cooled inconel manipulator is used for high temperature exposures up to $950^{\circ} \mathrm{C}$. Control of the air flow rate by a feedback circuit is used to regulate the sample temperature.

The samples are removed after exposure to the plasma and carried in air to a microbalance and surface analysis station. The erosion rates are determined by weight loss measurements. The measured sputtering yeilds have been well correlated to the OMA data on the amount of the sample material observed in the plasma. AES and SIMS surface analysis are conducted to determine the surface composition and impurity content. EMPA and RBS analysis are also used to determine the near surface composition.

\section{Materials Studies}

\subsection{Copper and Copper-Lithium}

The performance during plasma bombardment of copper, intenced for high heat flux applications in fusion experiments, is a good example of the response of a pure metal under erosion and redeposition conditions. Polished copper samples were exposed to $\mathrm{H}, \mathrm{He}$, and $\mathrm{Ar}$ plasmas. Surface modification does not appear to be dependent directly on the type of gas, but on the plasma parameters which determine the ionization of materials in the plasma and the Iedeposition characteristics. Plasma bombardment in both the erosion and redeposition regines produces the characieristic surface shown in Fig.3a. A typical heavily sputtered surface with enhanced grain boundaries and sparse sputter cone formation is produced. This surface forms 
independently of the sample temperature and plasma conditions when there is no deposition of low sputtering yield impurities. The deposition of molybdenum, iron, and nickel on the sample surface by sputtering of other samples inserted into the plasma does not significantly change this surface topography if the sample temperature is maintained below $100^{\circ} \mathrm{C}$. Deposited impurities are generally removed from the surface by the plasma bombardment except in the strong redeposition regime when the impurity ionization mean-free-path (MFP) is smaller than the sample size.

At sample temperatures higher than about $200^{\circ} \mathrm{C}$, and with Mo deposited on the sample, the surface shown in Fig. $3 b$ is formed. The ion flux, energy and fluence are the same for both $3 a$ and 3b. The low sputtering yield Mo acts as seeds for the development of dense cone structures. Surface analysis indicates that only a few percent of a monolayer of Mo coverage is present in Fig. 3b. The temperature dependence indicates that surface mobility of the Mo is important in forming the seed clusters that trigger cone formation.(17) This type of surface is only observed to form during redepostion conditions because the plasma is responsible for the transport of the seed material to the sample. The impurity source can be remotely located from the sample, and the impurity material sputtered into the flasma is ionized and carried to the sample. This transport, mixing and depostion of materials is an important characteristic of redeposition conditions. Redeposition of the same material as the sample does not result in strongly modified surfaces, but only a roughening of the classical structures.

The role of redeposition, independent of mixing of materials, is to significantly reduce the net erosion rate. $(18,19)$ Figure 4 is a plot of the percentage of the classical sputtering yield as a function of the ionization MFP for $\mathrm{Cu}$ (assumed sputtered with $1.7 \mathrm{eV}$ ) in the plasma. As the MFP becomes smatler, the net erosion is seen to decrease strongly. This effect is observed for $\mathrm{D}, \mathrm{He}$, and $\mathrm{Ar}$ bombardment of both $\mathrm{Cu}$ and stainless steel for ion energies in the range tested of 100 to $250 \mathrm{eV}$. In these experiments, the effective yield was reduced by up to a factor of ten. Operation with an ionization MFP of less than $10 \mathrm{~cm}$ is always observed to result in redeposition 
and reduced yields in PISCES. A simple model which describes this redeposition effect has been published.(18)

The high flux capability of PISCES has been used to test the performance of $\mathrm{Cu}$-Li alloys.(20-24) This material is described in detail elsewhere,(23) and reduces the sputtering yield of pure copper by producing a segregated surface layer of lithium. Since some fraction of the $\mathrm{Li}$ spulters as neutrals and escapes the surface, an investigation of the protective performance of this overlayer at high bombarding fluxes was undertaken. The experimental procedure is to insert the samples into the plasma at floating potential and allow the plasma to heat the material to the desired temperature by very low energy ion bombardment. The $\mathrm{Li}$ segregation is diffusion limited, and temperatures of 350 to $450^{\circ} \mathrm{C}$ are required to maintain the $\mathrm{Li}$ overlayer for ion fluxes above $10^{14} \mathrm{~cm}^{-2} \mathrm{sec}^{-1}$. A 100 volt bias is then applied to the sample and the $\mathrm{Li}$ and $\mathrm{Cu}$ line intensities monitored by the OMA system. Periodic breaks every hour during the exposure were made to weigh the samples.

To avoid confusing redeposition effects, the plasma was operated in the erosion mode with an ion flux to the sample of typically $5 \times 10^{17} \mathrm{~cm}^{-2} \mathrm{sec}^{-1}$. Helium plasmas were utilized to eliminate any ion species and chemical effects of hydrogen interaction on the surface. The weight loss of $6 \%$ and $11 \% \mathrm{Li}$ concentration samples as a function of the ion fluence is shown in Fig.5. Operation at temperatures below $400^{\circ} \mathrm{C}$ (not shown) with this ion flux produces essentially the same weight loss as pure copper. Early in the exposure period of samples at $450^{\circ} \mathrm{C}$, the weight loss for high $\mathrm{Li}$ concentration samples can exceed the amount of the pure $\mathrm{Cu}$ control samples. This is due to neutral $\mathrm{Li}$ evaporation, which is clearly seen as an intense red glow around the samples as the $\mathrm{Li}$ is excited in the plasma. The time history of the $\mathrm{Li}$ and $\mathrm{Cu}$ line intensities in the plasma for the $\mathrm{Cu}-11 \% \mathrm{Li}$ sample at $450^{\circ} \mathrm{C}$ is shown in Fig.6. Corresponding to every vacuum opening and thermal cycling of the samples, a large $\mathrm{Li}$ concentration is observed. The $\mathrm{Cu}$ line intensity in Fig. 6 indicates that $\mathrm{Cu}$ sputtering is at least a factor of 4-5 less than pure copper (the resolution of the measurement) during the first half hour of exposure when the $\mathrm{Li}$ concentration is high. 
After a sufficient time and plasma fluence, the measured weight loss and $\mathrm{Cu}$ intensity in the plasma settles to about half of the value of pure copper. This is roughly the same factor ultimately found for the $6 \% \mathrm{Li}$ sample, which did not exhibit the strong $\mathrm{Li}$ evaporation and $\mathrm{Cu}$ concentration reduction early in the experiments. Previous measurements(23) found reductions in the weight loss of $10 \% \mathrm{Li}$ samples by a factor of 2 to 4 . It is apparent that a weight loss measurement to determine the $\mathrm{Cu}$ erosion is suspect due to $\mathrm{Li}$ loss, and that vacuum openings strongly modify the material performance. Ion beam measurements of the yield of samples with Li concentrations over $15 \%$, utilizing a catcher foil technique, found reductions in copper sputtering by over a factor of 20.(24)

\subsection{Stainless Steel}

The modification of stainless steel surfaces by plasma bombardment in PISCES has been previously reported.(18) Plasma driven permeation of tritium through stainless steel samples has been found to depend on the surface roughness and composition.(25-27) Increased surface roughness was found to increase the re-emission of deuterium from the surface and decrease the permeation rate. To examine the effectiveness of strongiy modified surfaces as a tritium barrier, type 304 stainless steel samples were exposed to $100 \mathrm{eV} \mathrm{Ar}+$ bombardment at a flux of about $2 \times 10^{18} \mathrm{~cm}^{-2} \mathrm{sec}^{-1}$ for one hour. The ionization MFP for iron and nickel for these experiments was on the order of $1-2 \mathrm{~cm}$, resuiting in strong redeposition conditions. The weight loss reduction measured for these runs is inclided in Fig.4. The sample temperature was regulated to $400^{\circ} \mathrm{C}$.

The surface structures of the stainless steel samples are shown in Fig.7. As with $\mathrm{Cu}$, the surface morphology is determined by the sample temperature and the deposition of low sputtering yield impurities. In Fig.7a, the samples were bombarded at a temperature of $30^{\circ} \mathrm{C}$, and the typical heavily sputtered surface was produced. No conte formation is observed either with or without the deposition of small amounts of Mo.(17) In contrast, the samples operated at $400^{\circ} \mathrm{C}$ 
with Mo deposition formed the surface shown in Fig.7b in less than one minute. Copper deposition on the sample does not trigger this cone structure formation.

The samples with the surface structure of Fig.7b were analyzed for deuterium re-emission and tritium permeation(25-27) at SNLL. A detailed description of the experimental procedure and results can be found elsewhere.(17) Compared to unexposed samples, the re-emission is found to increase for the modified sample, and the permeation is lower by about a factor of three. The increased re-emission and decreased tritium permeation of the exposed, roughened samples are consistent with a measured surface area increase (by BET) after exposure of about a f:ctor of ten.

\subsection{Graphite}

The performance of graphite during high flux and fluence plasma bombardment is of great interest for present confinement devices. Several grades of Poco, ATJ and pyrolytic graphite have been tested in PISCES. The Poco and ATJ graphites examined in our experiments are found to have similar sputtering yields and surface morphology changes. The results reported here are from experiments with Poco AXF-5Q graphite.

The samples are cleaned by immersion for one half hour in alcohol in an ultrasonic cleaner. After drying, the samples are placed in PISCES and heated by exposure at floating potential to the plasma for fifteen minutes at a temperature of at least $500^{\circ} \mathrm{C}$, and usually $100^{\circ} \mathrm{C}$ higher than the planned testing temperature. The hydrogen plasma used for this outgasing phase typically consists of $0.25 \mathrm{~A} / \mathrm{cm}^{2}$ of ion bombardment at a floating potential of $20-30 \mathrm{eV}$. Visual observation of the samyle during heating shows a strong outgassing at a temperature of about $400-450^{\circ} \mathrm{C}$, which appears as a bright yellow glc ${ }^{2}$ around the sample. This seems to be the major outgassing phase observed during our experiments (up to $950^{\circ} \mathrm{C}$ ) for Poco and ATJ graphite. After outgassing, the samples are weighed and inserted back in PISCES for tesis. Typically, heating and cooling cimes of five minutes and bombardment times of 30-60 minutes are used. 
The surface topography of Poco graphite changes strongly during high fluence bombardment. Fig. 8a shows a scanning electron microscope photograph of a sample maintained at $60^{\circ} \mathrm{C}$ during bomardment by $100 \mathrm{eV}$ hydrogen ions at a flux of $1.8 \times 10^{18} \mathrm{particles} / \mathrm{cm}^{2} \mathrm{sec}$. This picture was taken after a fluence of $3 \times 10^{21}$ particles $/ \mathrm{cm}^{2}$ was accumulated, but it is almost indistinguishable from the original cleaned and outgassed surface. After a fluence of $3 \times 10^{22}$ particles $/ \mathrm{cm}^{2}$ of $100 \mathrm{eV}$ hydrogen ions, the porous and hot:ycombed surface shown in Fig. $8 \mathrm{~b}$ has de:-loped. Preliminary experiments indicate that the sputtering yeild of this honeycomb type surface can be 3 to 4 times lower that that shown in Fig.8a

Surface analysis of this sample detected a small amount of copper (less than $5 \%$ ) on the surface. This copper deposition from the plasma lump was eliminated by tuming the plasma off during sample insertion and retraction, and was not found on the samples used in subsequent experiments reported bere. However, very high power plasna operation can result in the sputtering and transport of the dump and manipulator materials to the samples. This is illustrated in Fig.9, where nickel from the inconel sample holder was deposited on the sample during an 18 minute bombardment in helium with a flux of $2.4 \times 10^{13} \mathrm{~cm}^{-2} \mathrm{sec}^{-1}$. The $2 \times 10^{12} \mathrm{~cm}^{-3}$ plasma density and $23 \mathrm{eV}$ electron temperature in this experiment resulted in ionization of the sputtered nickel, and transport and deposition on the sample. The metal impurities are obseried to form clusters or beads on the surface. This occurs during 1.ormal deposition of impurities on graphite, and is not necessarily a feature of tokamak disnuptions where pieces of material are splashed onto the surface. To completely eliminate the deposition of impurities at high power in PISCES, the wall materiais are generally replaced by the same material as the sample.

The low energy dependence of the sputtering yield of Poco graphice was investigated in PISCES. Previous experiments(28) at IPP, Garching indicated that the yield at energies lower than $100 \mathrm{eV}$ would decrease following the physical sputtering model. Exposure of a sample maintained at $200^{\circ} \mathrm{C}$ to $50 \mathrm{eV}$ deuterium ions at a flux of $1 \times 10^{18}$ particles/em ${ }^{2} \mathrm{~s} . \mathrm{C}$, composed of about $75 \% \mathrm{D}^{+}, 20 \% \mathrm{D}_{2}+$, and $5 \% \mathrm{D}_{3}+$ determined from mass analyzer data, resulted a yield of over $2 \times 10^{-2}$. This value is roughly 5 timiss higher than predicted.(28) The high sputtering yield 
cisicrved at low energy was subsequently investigated in detail by Roth and Bohdansky.(29) The sputtering at low energy in their experiments corresponded to an increase in the RGA signal for methane, suggesting a new chemical sputtering regime exisits at low energy and low temperatures.

Chemical sputtering of graphite has been investigated in ion beam facilities(30), and has been reviewed by Roth.(31) It has been suggested that chemical sputtering will be suppressed at high ion fluxes where hydrogen recombination may dominate the surface processes. In PISCES, $100 \mathrm{eV}$ hydrogen ions (about $70 \% \mathrm{H}^{+}, 20 \% \mathrm{H}_{2}^{+}, 10 \% \mathrm{H}_{3}+$ ) at a flux of $1.5 \times 10^{18}$ particles $/ \mathrm{cm}^{2} \mathrm{sec}$ were used to investigate the chemical sputtering rates. The plasma electron temperature was set at $6 \mathrm{eV}$ to avoid any ionization of the hydrocarbons produced at the surface. The calculated ionization MFP for methane(32), assumed produced with an energy corresponding to the sample temperature, is $15-20 \mathrm{~cm}$. This indicates that the erosion regime (see Fig.4) is achieved. The samples were exposed to a fluence of less than $5 \times 10^{21}$ particles $/ \mathrm{cm}^{2}$ to avoid surface morphology modification effects on the yield measurements. Figure 10 shows the sfuttering yield dependence on the sample temperature. The low temperature yield data points agree well with the ion beam data shown(29), which was measured with a flux two orders of magnitude lower than in PISCES. The sputtering yield increases by a factor of four at a temperature of $600^{\circ} \mathrm{C}$, and falls to near the low temperature value at about $850^{\circ} \mathrm{C}$. Hydrogen and deuterium experiments in PISCES produce about the same factor of four increase in the yield at about $600^{\circ} \mathrm{C}$. This factor of four increase with $100 \mathrm{eV}$ ion bombardment in PISCES agrees exactly with the deuterium results of Roth and Bohdansky(29) at $100 \mathrm{eV}$ and the lower fluxes. It is clear from these experiments that chemical effects are still important at high fluxes.

Chemically sputtered hydrocarbons are relatively easy to ionize and redeposit compared to carbon because they are released with an energy corresponding to ciose to the sample temperature.(33) The calculated ionization MFP for methane from a $400^{\circ} \mathrm{C}$ sample, and for carbon (assumed sputtered with $3.5 \mathrm{eV}$ ), is shown in Fig.11 versus the ion flux to the sample in PISCES for a $10 \mathrm{eV}$ electron temperature. Operation at fluxes of over $0.2 \mathrm{~A} / \mathrm{cm}^{2}$ (corresponding 
to a plasma density of roughly $10^{12} \mathrm{~cm}^{-3}$ ) results in significant redeposition for methane at this electron temperature. A series of sample exposures in the moderate redeposition regime (ionization MFP approximately $5 \mathrm{~cm}$ ) were performed to examine the reduced chemical sputtering yields. A flux of $0.3 \mathrm{~A} / \mathrm{cm}^{2}$ of $100 \mathrm{eV}$ hydrogen ions from a $13 \mathrm{eV}$ electron temperature plasma was used to bombard the samples. The results are shown in Fig.10, where the effective sputtering yields are seen to be reduced by the hydrocarbon redeposition. The intensity of $\mathrm{CH}_{4}$ and $\mathrm{CH}$ lines in the plasma observed by the OMA follow the sputtering yield curves of Fig.10. Since fragmentation of $\mathrm{CH}_{4}$ and $\mathrm{CH}_{3}$ occurs even faster than ionization(32) it is likely that the $\mathrm{CH}$ observed in the plasma is from the breakup of these molecules.

Redeposition of methane is observed to modify the appearance of the surfaces. Samples that have been chemically sputtered and redeposited at high temperatures have a black, felt-like surface when examined visually, compare to a relatively smooth appearance to the eye for physically sputtered surfaces. Figure 12 a shows a typical sample surface bombarded with the plasma parameters of Fig. 10 (erosion dominated regime) at a sample temperature of $60^{\circ} \mathrm{C} . \mathrm{A}$ sample from the redeposition regime of Fig. 10 at $600^{\circ} \mathrm{C}$ is shown in Fig. $12 \mathrm{~b}$. While the gross structure of the surface is similar, the chemically eroded and redeposited surface has very fine features. The redeposited graphite tends to be scot-like and loosly bound, and can be easily remotred from the surface by soft rubbing. Operation in helium with virtually identical redeposition conditions as the sample of Fig. $12 \mathrm{~b}$ does not produce the felt-like surface, indicating that chemical effects are responsible.

\section{Conclusions}

The study of erosion and redeposition of materials during plasma bombardment in a controlled environment is possible in PISCES. Redeposition of metals does not strongly change the morphology compared to heavily sputtered surfaces, but does generally roughen the surface. Impurity deposition, which can result from operation in the redeposition mode where the plasma has sufficient density and electron temperature to ionize and transport other materials to the 
samples, produces gross surface topography modification. This plasma regime can also riodify the composition of the material and alter the surface properties. Redeposition reduces the effective sputtering yield, with the amount depending on the quantity of material that can escape the magnetic flux wbes that connect to the samples.

Stidies of the performance of graphite produced some surprising and important results. Chemical sputtering of graphite at low temperature $\left(<100^{\circ} \mathrm{C}\right)$ by hydrogen ions with less than $100 \mathrm{eV}$ of energy was first observed in PISCES. Chemical sputtering was found to occur at high bombarding fluxes, with the increase in the yield agreeing with low flux ion beam experiments. Hydrocarbons formed during chemical sputtering are ionized and fragmented close to the surfaces in plasmas with densities of over $10^{12} \mathrm{~cm}^{-3}$ and electron temperatures of $10 \mathrm{eV}$ or higher. This suggests that it is unlikely that methane can penetrate the edge plasma in present tokamak experiments. Redeposition of hydrocarbons reduces the effective sputtering yield of graphite, and produces felt-like surfaces of weakly bound carbon soot. Metal impurities plasma deposited on graphite samples form clusters, similar to the results from analysis of tokamak limiters.

\section{Acknowledgments}

The authors would like to thank T.Sketchley, K.Andrews, and V.Low 'or valuable technical assistance in the performance of these experiments. Work was supported in part by the U.S. D.O.E. under contracts \# P.A. DE-AT03-84ER52104, and DE-AC04-76DP00789. 
TABLE 1. Typical operating parameters of PISCES.

\begin{tabular}{|c|c|}
\hline Gas Type & $\mathrm{H}, \mathrm{D}, \mathrm{He}, \mathrm{N}, \mathrm{AT}$ \\
\hline Operation Time & Continuous \\
\hline Flux Range (ions $/ \mathrm{cm}^{2} \mathrm{sec}$ ) & $10^{17}-2 \times 10^{19}$ \\
\hline Plasma Density $\left(\mathrm{cm}^{-3}\right)$ & $10^{11}-10^{13}$ \\
\hline Electron Temperature (eV) & $5-24$ \\
\hline Plasma Area $\left(\mathrm{cm}^{2}\right)$ & $50-80$ \\
\hline Sample Bias (Volts) & $25-500$ \\
\hline Base Pressure (torr) & $1 \times 10^{-7}$ \\
\hline Sarnple Temperature Range $\left({ }^{\circ} \mathrm{C}\right.$ ) & $20-950$ \\
\hline
\end{tabular}




\section{EIGURE CAPTIONS}

1. Top view of the PISCES experimental layout showing the diagnostics and their locations.

2. Electron temperature versus plasma density presently available (inside the curves) in PISCES in hydrogen. The open circles are data points correspond to the minimum gas flow cases for discharge stability, and the filled squares correspond to the maximum gas flow.

3. Surface structure of copper after bombardment by $100 \mathrm{eV}$ helium ions and redeposition of the sputtered copper. Similar surfaces are produced by hydrogen and argon plasmas. Surface (a) is maintained at a temperature below $100^{\circ} \mathrm{C}$ and occurs with and without Mo deposition. Surface (b) formed during plasma bombardment with Mo seeding and a sample temperature of $400^{\circ} \mathrm{C}$. 4. Copper anä stainless steel sample weight loss, normalized to the erosion sputtering yields in the literature, versus ionization mean-free-path for $100 \mathrm{eV}$ plasma bombandment. Redeposition of the sample material by plasmas with ionization mean-free-paths of less than $15 \mathrm{~cm}$ reduces the net erosion.

5. Weight loss of copper-lithium alloys, normalized to pure copper weight loss, versus fluence of $100 \mathrm{eV}$ helium ions. After an initial high weight loss attributed to $\mathrm{Li}$ loss, the yield for $\mathrm{Cu}-\mathrm{Li}$ settles to about half the value found for copper during these experimentsi.

6. Copper and lithium line intensities in the plasma versus ion fluence for the $\mathrm{Cu}-11 \% \mathrm{Li}$ sample at $450^{\circ} \mathrm{C}$.

7. Surface structure of stainless steel after exposure to $100 \mathrm{eV}$ argon ions with redeposition of the sputtered material. Surface (a) is maintained at a temperature below $100^{\circ} \mathrm{C}$ and $o c c u r s$ with and without Mo deposition. Surface (b) formed during plasma bombardment with Mo seeding and a sample temperature of $400^{\circ} \mathrm{C}$.

8. Surface structure of Poco graphite after bombardment at $60^{\circ} \mathrm{C}$ by $100 \mathrm{eV}$ hydrogen ions at a flux of $1.5 \times 10^{18}$ particles/cm ${ }^{2}$ sec. Surface (a) is produced after fluence of $3 \times 10^{21} \mathrm{~cm}^{-2}$, and is similar in structure to unexposed samples. The porous and honeycombed surface in (b) resulted after a fluence of $3 \times 10^{22} \mathrm{~cm}^{-2}$ had been accumulated. 
9. Nickel impurities deposited on Poco graphite at $200^{\circ} \mathrm{C}$ during exposure in PISCES to a helium plasma with $2 \times 10^{12} \mathrm{~cm}^{-3}$ density and $: 3 \mathrm{eV}$ electron temperature. The impurities are transported by the plasma to the surface (no direct sputtering path), an." form beads and clusters on the surface.

10. Graphite sputtering yield versus temperature comprring pure erosion and "partial" redeposition regimes of chemically sputtered hydrocartons. Redeposition of a fraction of the hydrocarbons lowers the net erosion of the samples.

11. Cílculated ionization mean-free-path for carbon and methane from a $400^{\circ} \mathrm{C}$ sample versus ion flux from a $10 \mathrm{eV}$ hydrogen plasma. Significant redeposition of methane and hydrocarbons uccurs at fluxes of about $0.3 \mathrm{~A} / \mathrm{cm}^{2}$, corresponding to a plasma density of $10^{12} \mathrm{~cm}^{-3}$. Carbon requires much higher electron temperatures and densities to interact with the plasma close to the samples.

12. Redeposition of hydrocarbons modifies the fine surface structure and leaves weakly bound, felt-like surfaces. In the erosion regime, after $100 \mathrm{eV}$ hydrogen ion bombardment, a $50^{\circ} \mathrm{C}$ sample is shown in (a). This standard surface also results from helium plasma exposures at all temperatures. By increasing the electron temperature to $14 \mathrm{cV}$ in hydrogen, the hydrocarbons are redeposited and produce the surface shown in (b). 


\section{REFERENCES}

1. Recently reviewed by: G. Staudenmaier, J. Vac. Sci. Technol. A, 3 (1985) 1091.

2. E. Taglauer, J. Nucl. Mat., $128 \& 129$ (1984) 141.

3. S.A.Cohen, R.Budny, G.M.McCracken, et al., Nucl. Fusion, 21 (1981) 233.

4. P.Staib, et al., J. Nucl. Mat., $111 \& 112$ (1982) 173.

S. T.Yamashina and M.Mohri, J. Nucl. Mat, $128 \& 122$ (1984) 208.

6. TFR Group, J. Nuel. Mat, $128 \& 129$ (1984) 292.

7. R.Behrisch, P.Borgesen, J.Ehrenberg, et al., J. Nucl. Mat., $128 \& 122$ (1984) $4 \%$.

8. Y.Hirohata, M.Mohri, T.Yamashina, et al., J. Nucl. Mat., $128 \& 122$ (1984) 477.

9. E.Franconi, M.Barteri, G.M.Ingo, J. Nucl. Mat., 128\&129 (1984) 48 C.

10. M.Nishikawa, H.Yokomizo, A.Kitsunezaki, et al., J. Nucl. Mat., $128 \& 122$ (1984) 493.

11. B.L.Doyle, W.R.Wampler, H.F.Dylla, et al., J. Nucl, Mat., $128 \& 129$ (1984) 955.

12. H.H.Andersen and H.L.Bay, Sputtering Yield Measurements, in: Sputtering by Particle

Bombardment I, Ed. R. Behrisch (Springer-Verlag, Berlin, 1981) p.145-218.

13. R.A.Langley, J.Bohdansky, W.Eckstein, et al., Nucl.Fusion Special Issue (1984) 1683.

14. D.M.Goebel, G.A.Campbell, R.W.Conn, J. Nucl. Mat., 121 (1984) 277.

15. D.M.Goebel, and R.W.Conn, J. Nucl. Mat, $128 \& 129$ (1984) 249.

16. D.M.Goebel, Y.Hirooka, T.A.Sketchley, Rev.Sci.Instrum., 56 (1985) 1717.

17. Y.Hirooka, D.M.Goebel, R.W.Conn, et al., Froc. Workshop on Surface Modification by Plasma Surface Interactions, Princeton, NJ, May 1-2, 1986, to be published in Nucl. Instrum. and Methods B.

18. Y.Hirooka, D.M.Goebel, W.K.Leung, et al., Proc. 2nd Intl. Conf. on Fusion Reactor Materials, Chicago, II, April i3-17, to be published in J. Nucl. Mat.

19. J.N.Brooks, Nucl. Tech. Fusion, 4 (1983) 33.

20. A.R.Krauss, D.M.Gruen, J. Nucl. Mat., 103\&104 (1981) 239.

21. A.R.Krauss, D.M.Gruen, A.B.DeWald, J. Nucl. Mat., 121 (1984) 398. 
22. A.R.Krauss, D.M.Gruen, N.Q.Lam, et al., J. Nuel. Mat, $128 \& 129$ (1984) 398.

23. A.R.Krauss, D.M.Gruen, M.H.Mendelsohn, (these proceedings).

24. J.Bohdansky (private communication).

25. K.L.Wulson and M..Baskes, J. Nucl, Mat, 1118.112 (1982) 622.

26. A.E.Pontau, M.I.Baskes, K.L.Wilson, et al., J. Nucl. Mat., $111 \& 112$ (1982) $65 \mathrm{~L}$.

27. R.A.Causey, R.A.Kerst, B.E.Mills, J. Nucl. Mat, 1228123 (1984) 1547.

28. J.Bohdansly, H.L.Bay, W.Ottenberger, J. Nucl. Mat., 76 (1978) 163.

29. J.Roth and J.Bohdansky, Proc. Workshop on Surface Modification by Plasma Surface Interactions, F rinceton, NJ, May 1-2, 1986, to t , pulblished in N1'cl. $]$; itu in and Methods B.

30. E.Vietzke, K.Flaskamp, V.Phillipps, J. Nucl. Mat., $128 \& 129$ (1984) 545.

31. J.Roth, Chemical Sputtering, in: Sputtering by Particle Bombardment I, Ed. R. Behrisch (Springer-Verlag, Berlin, 1981) p.91-146.

32. W.D.Langer, Nucl. Fusion, 22 (1982) 751.

33. B.Schweer, D.Rusbuldt, E.Hintz, et al., J. Nucl. Mat, 23 (1980) 357. 


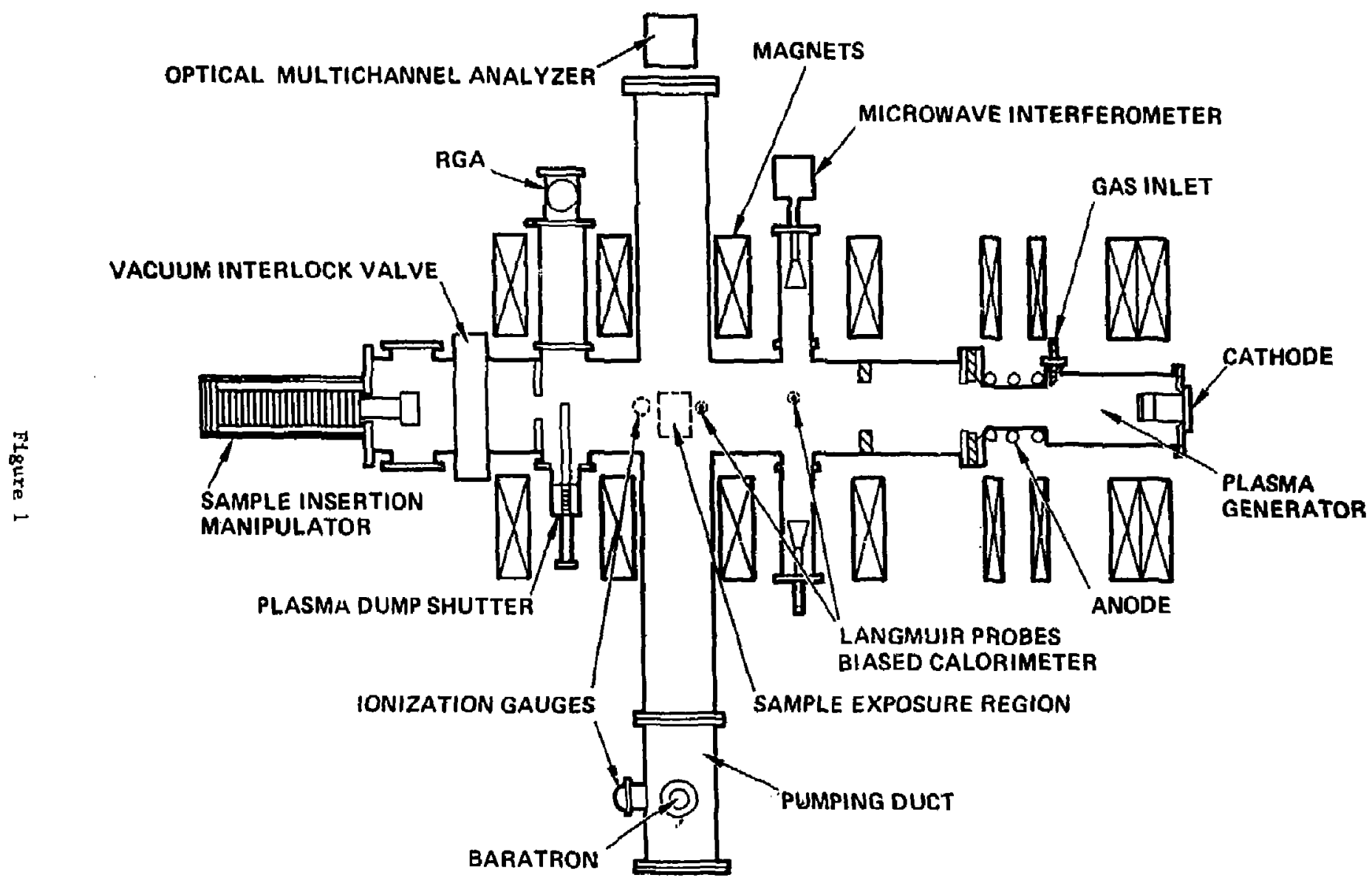




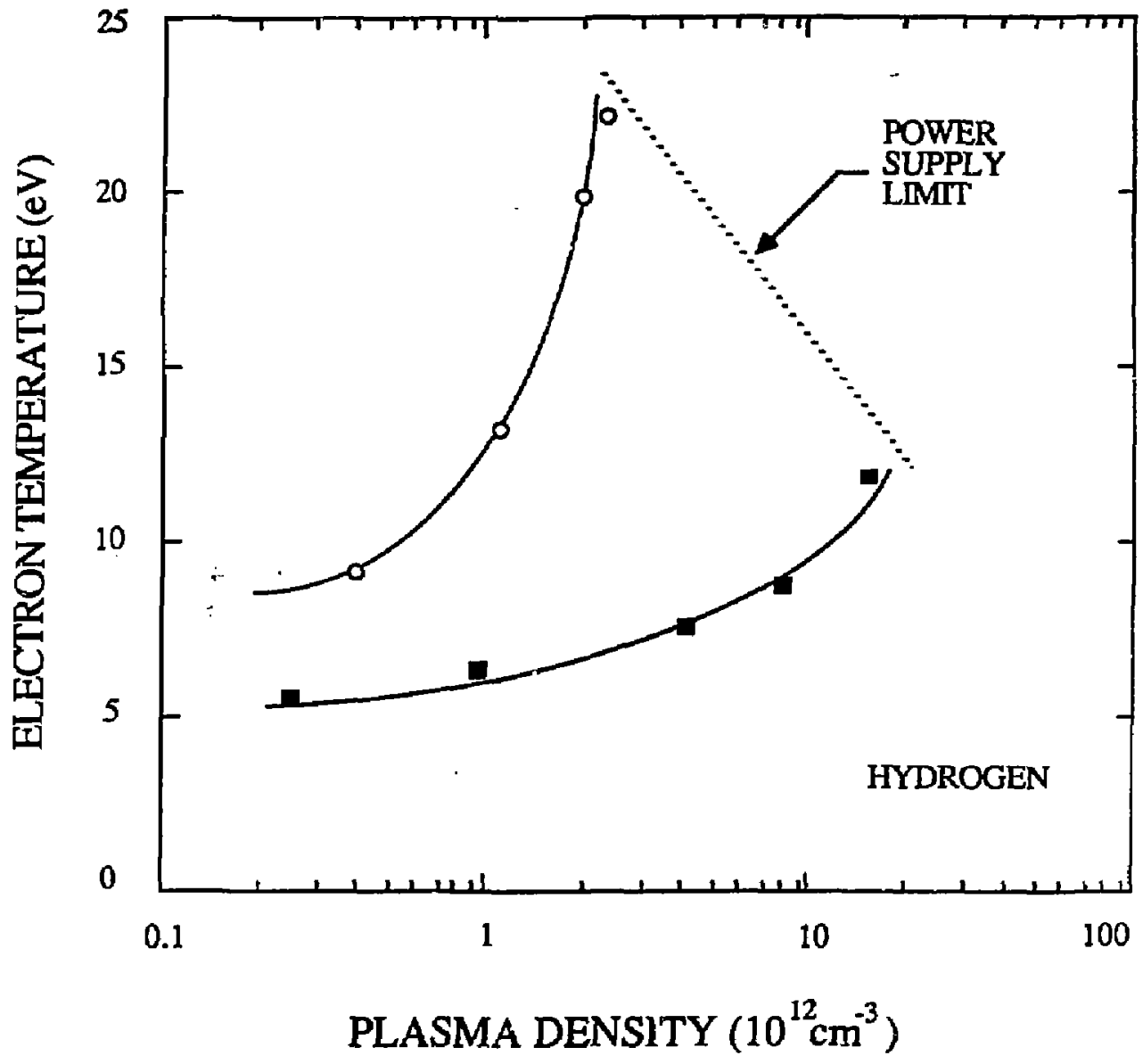

Figure 2 


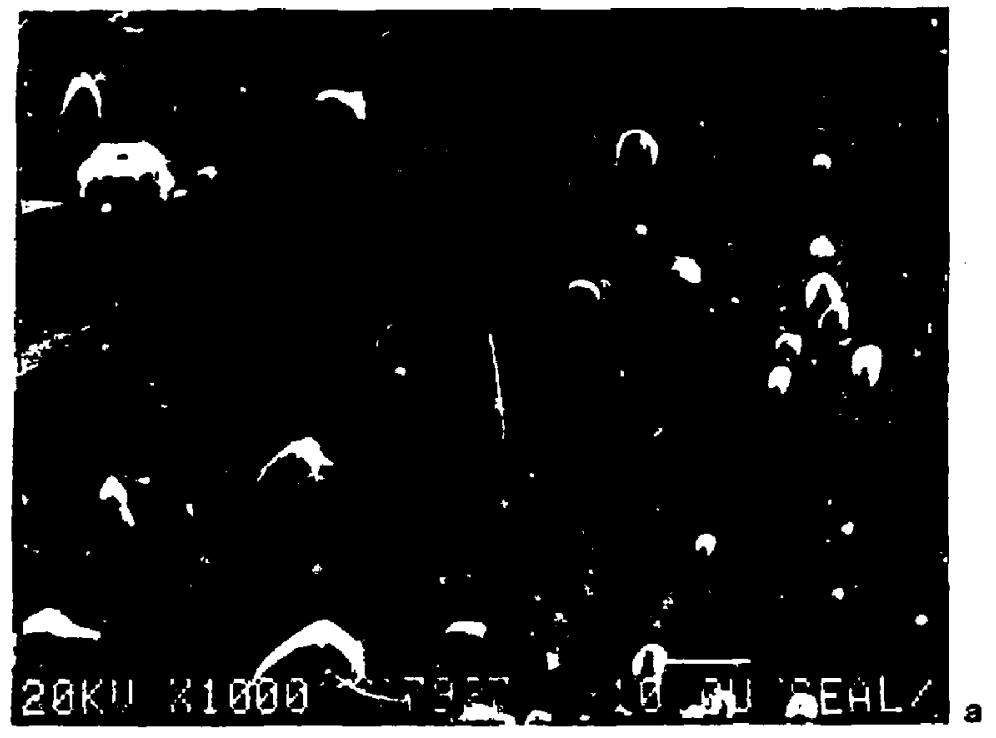

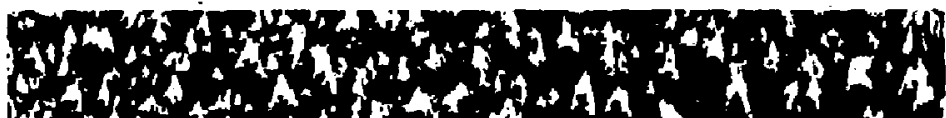
$\because$

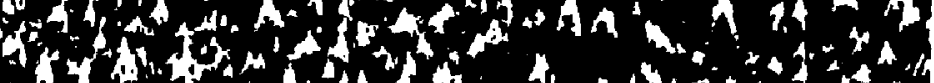

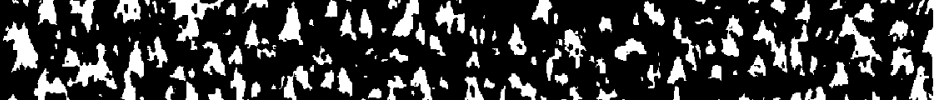

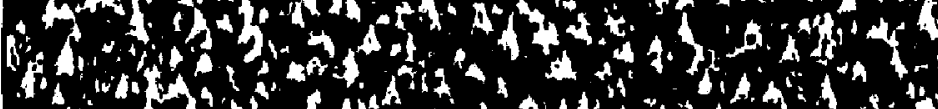

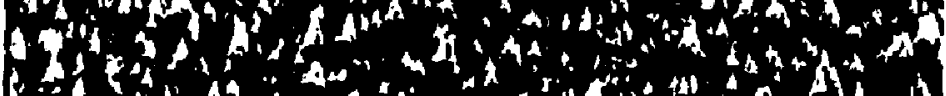

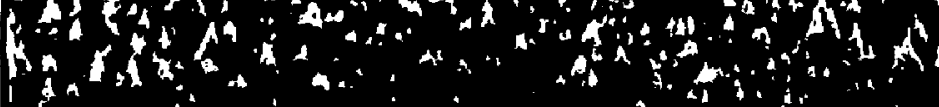
ats

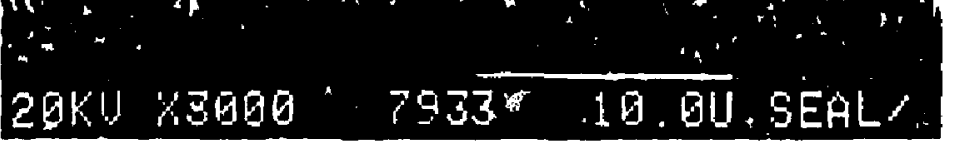




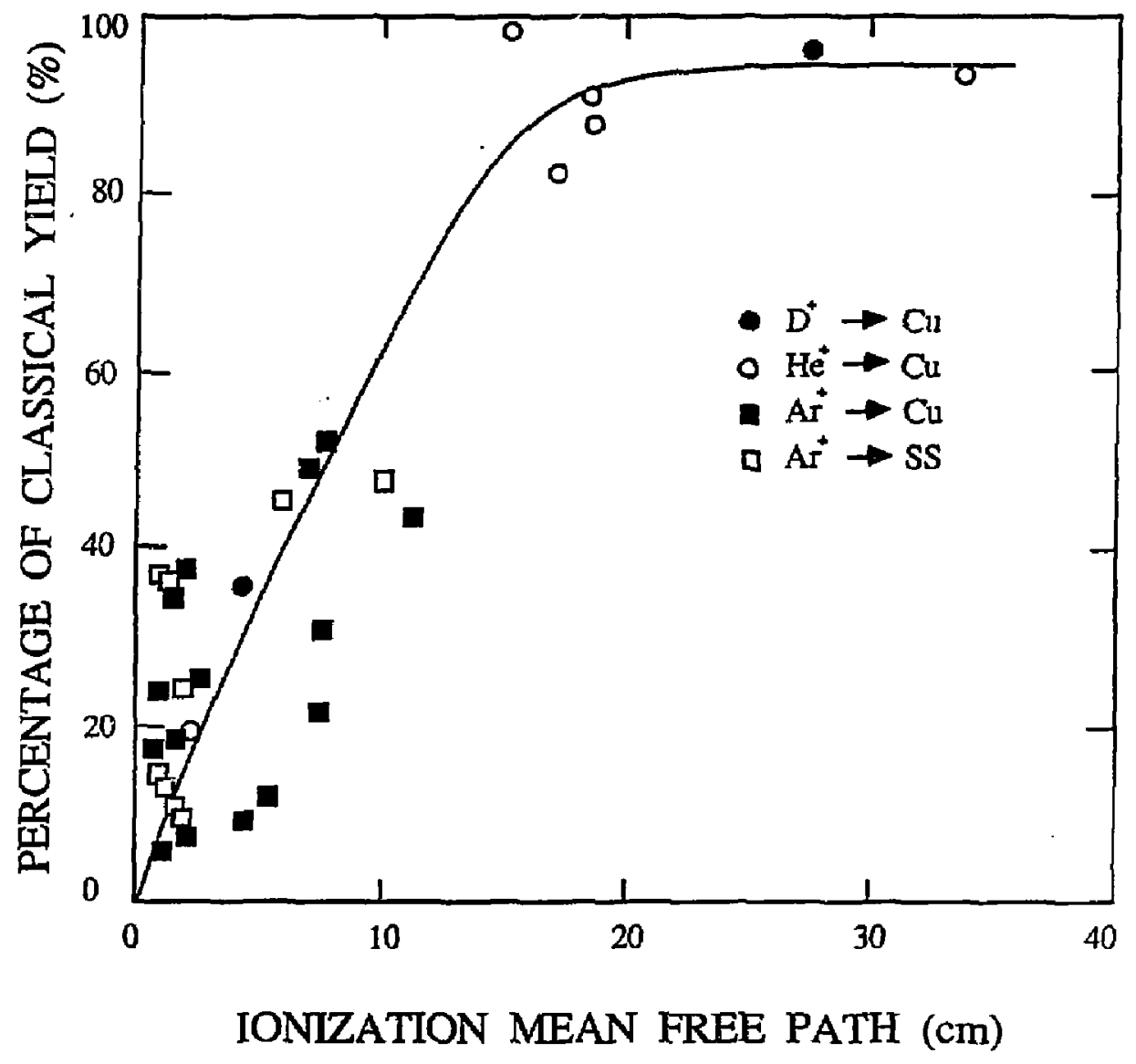

Figure 4 


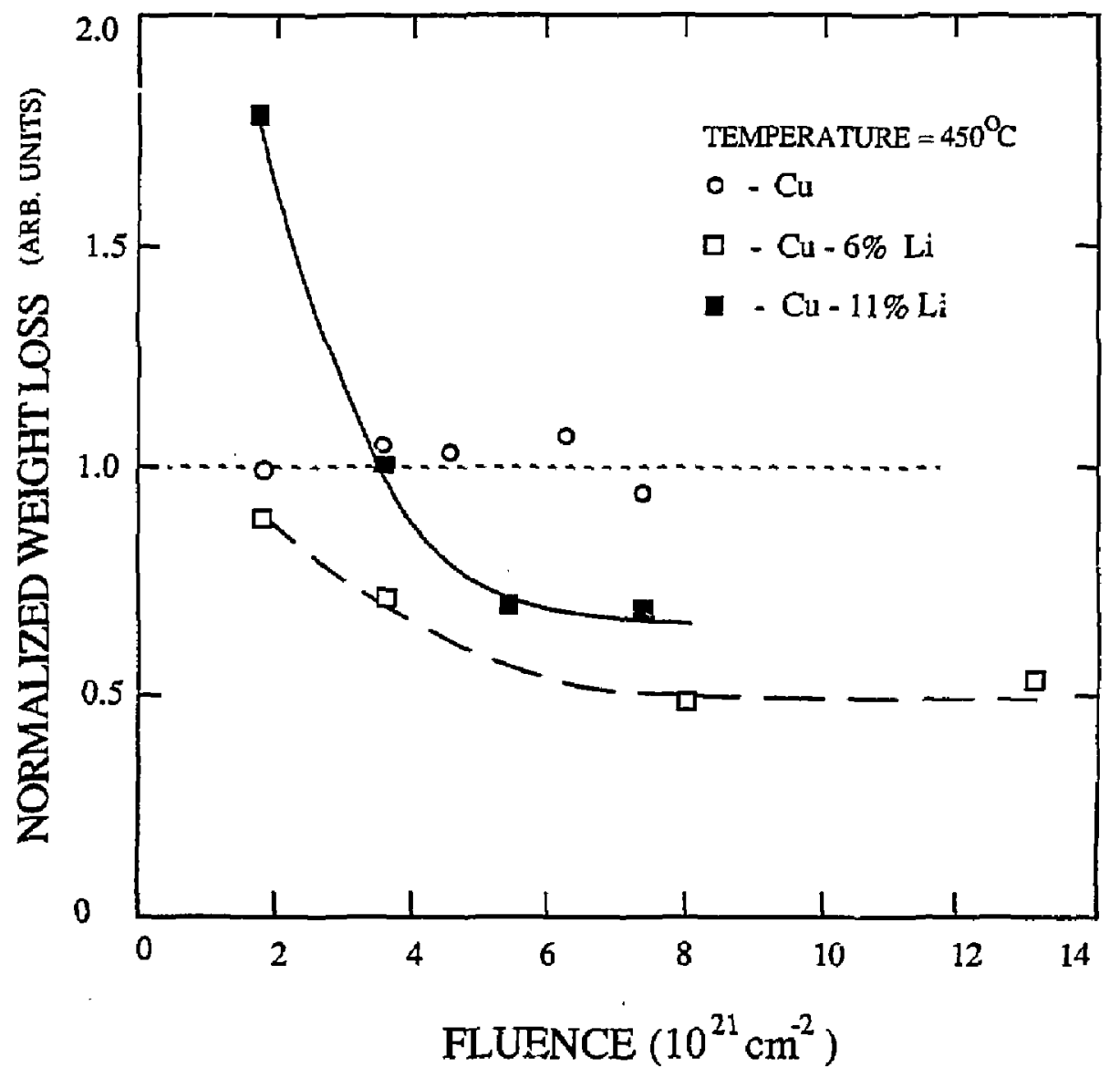

Figure 5 


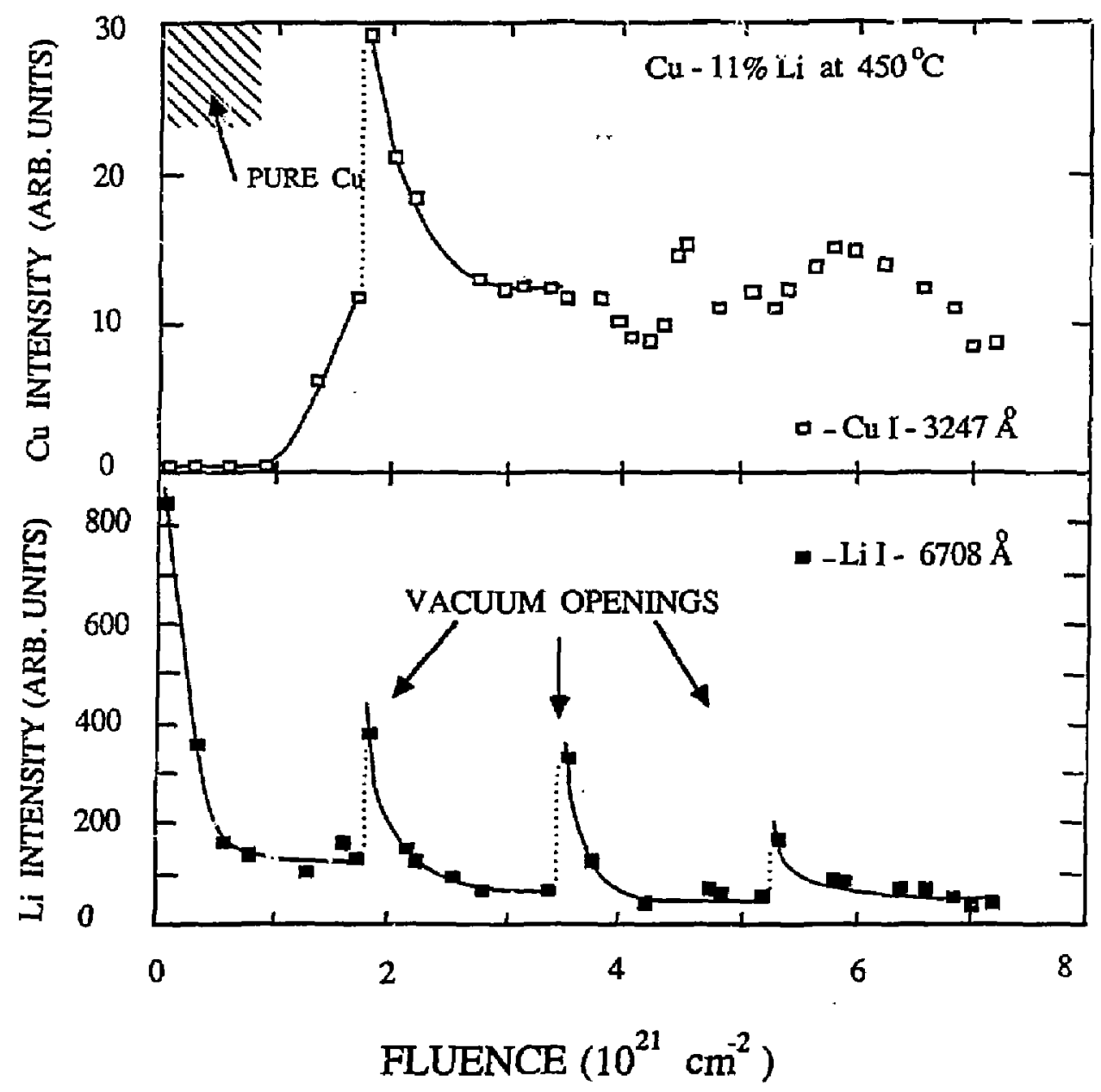

Figure 6 


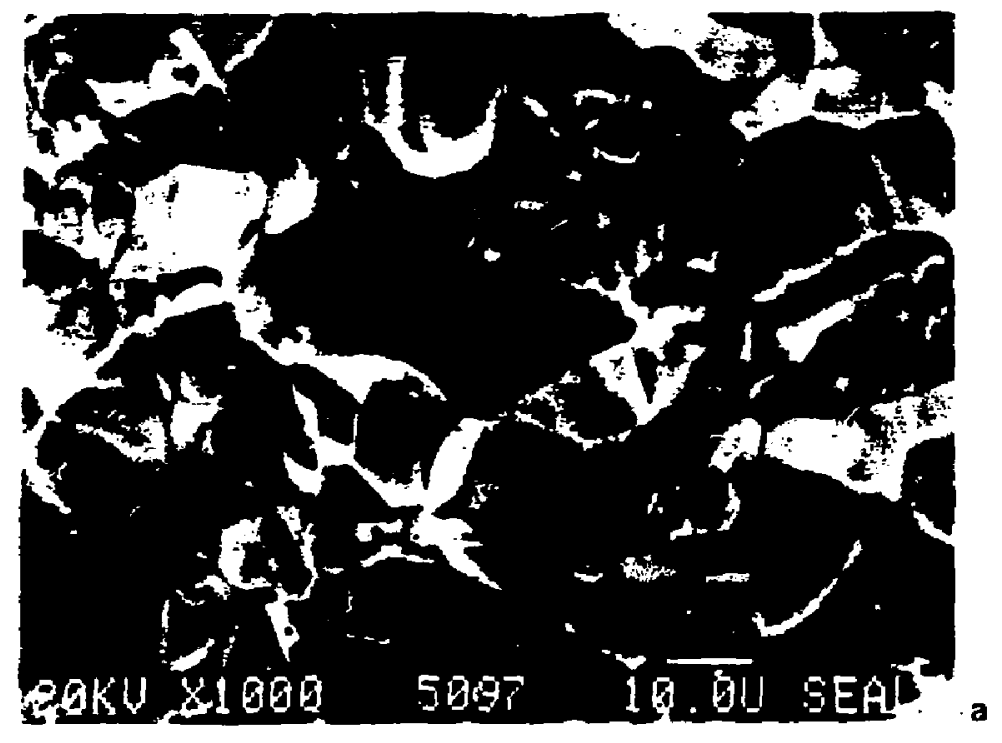

(3)

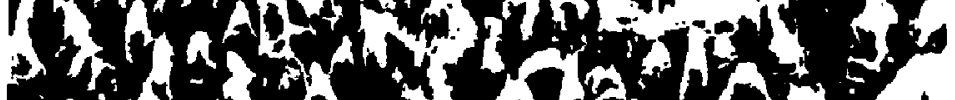

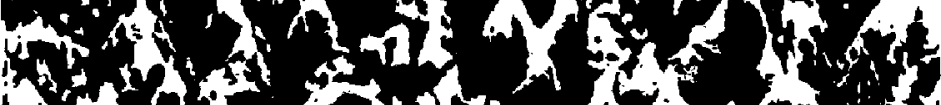

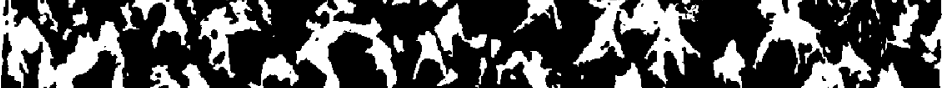

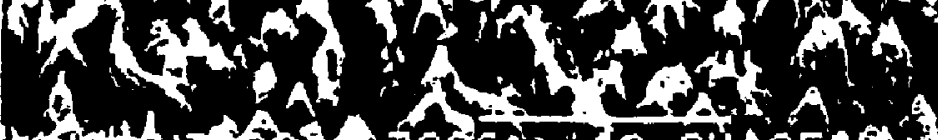

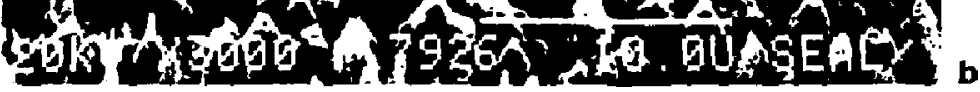



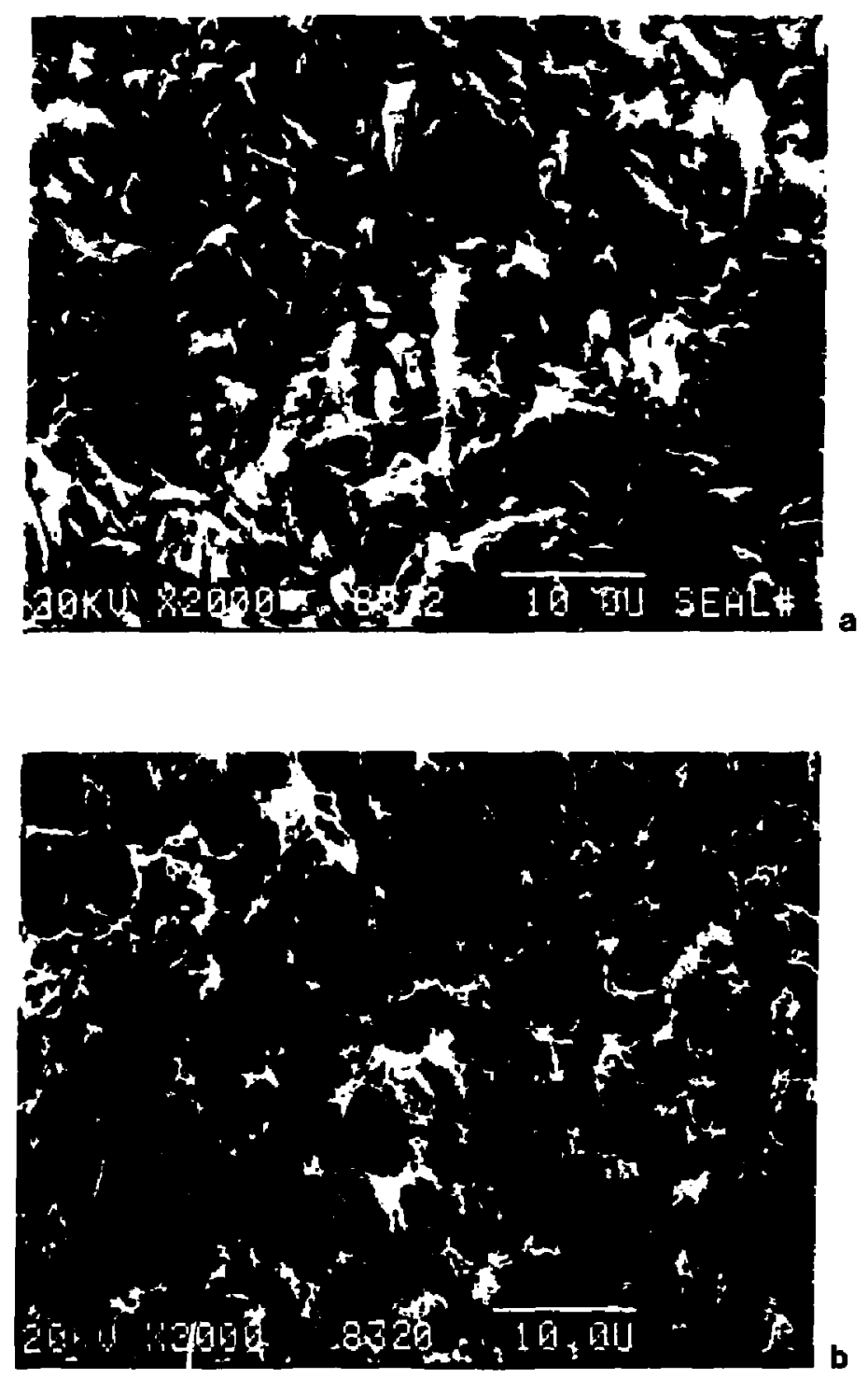

Figure 8 


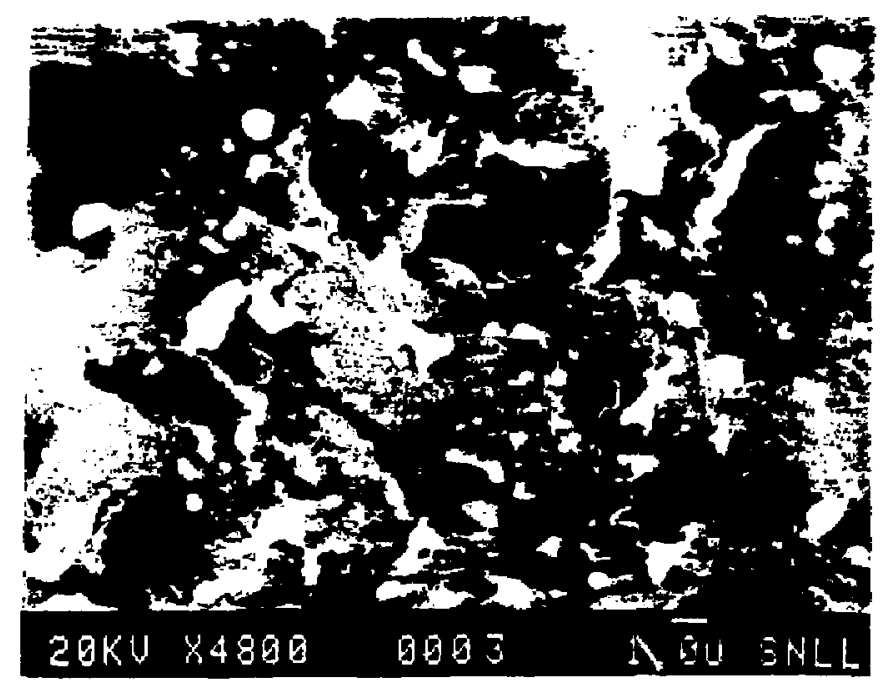

Figure 


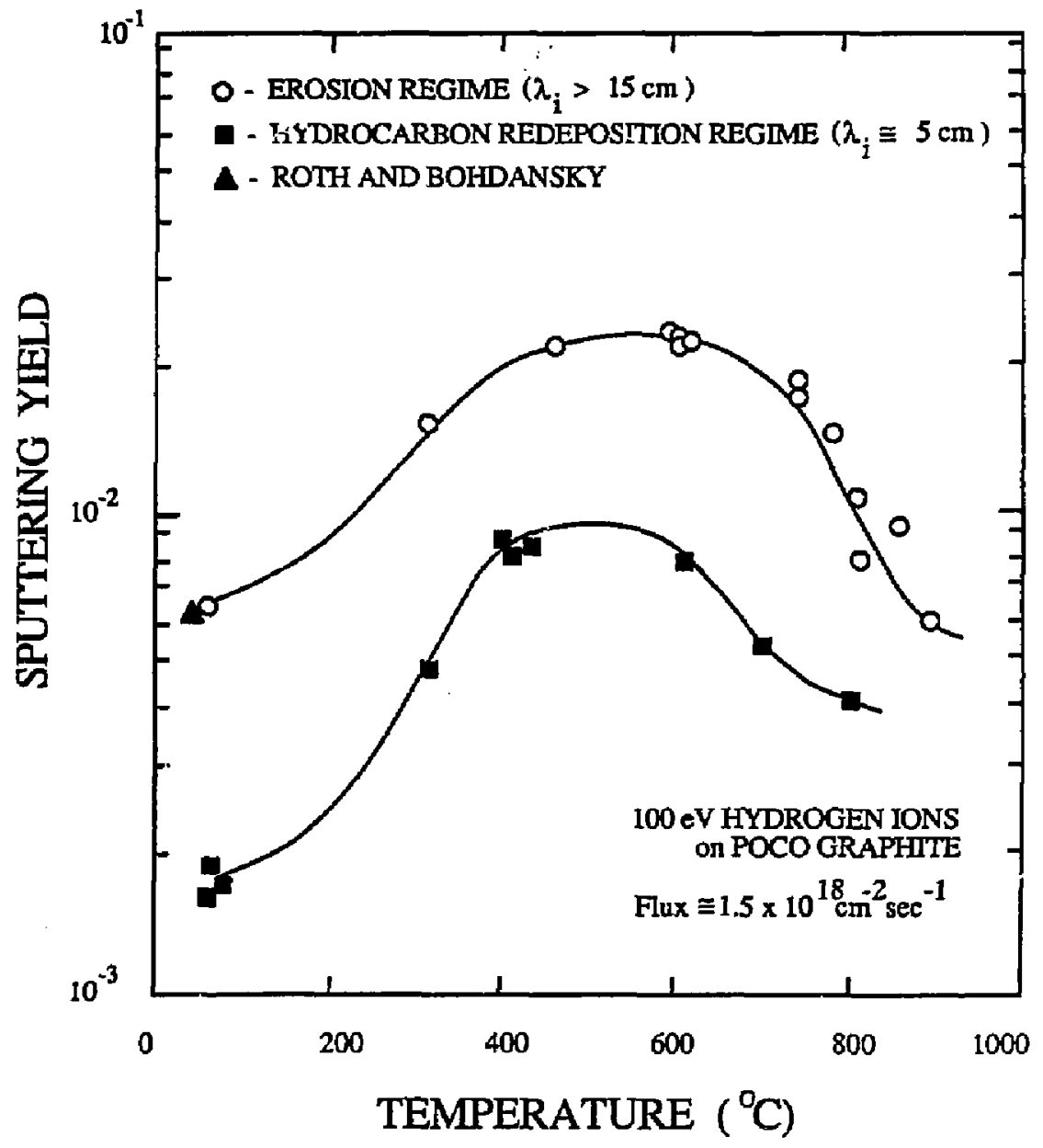

Figure 10 


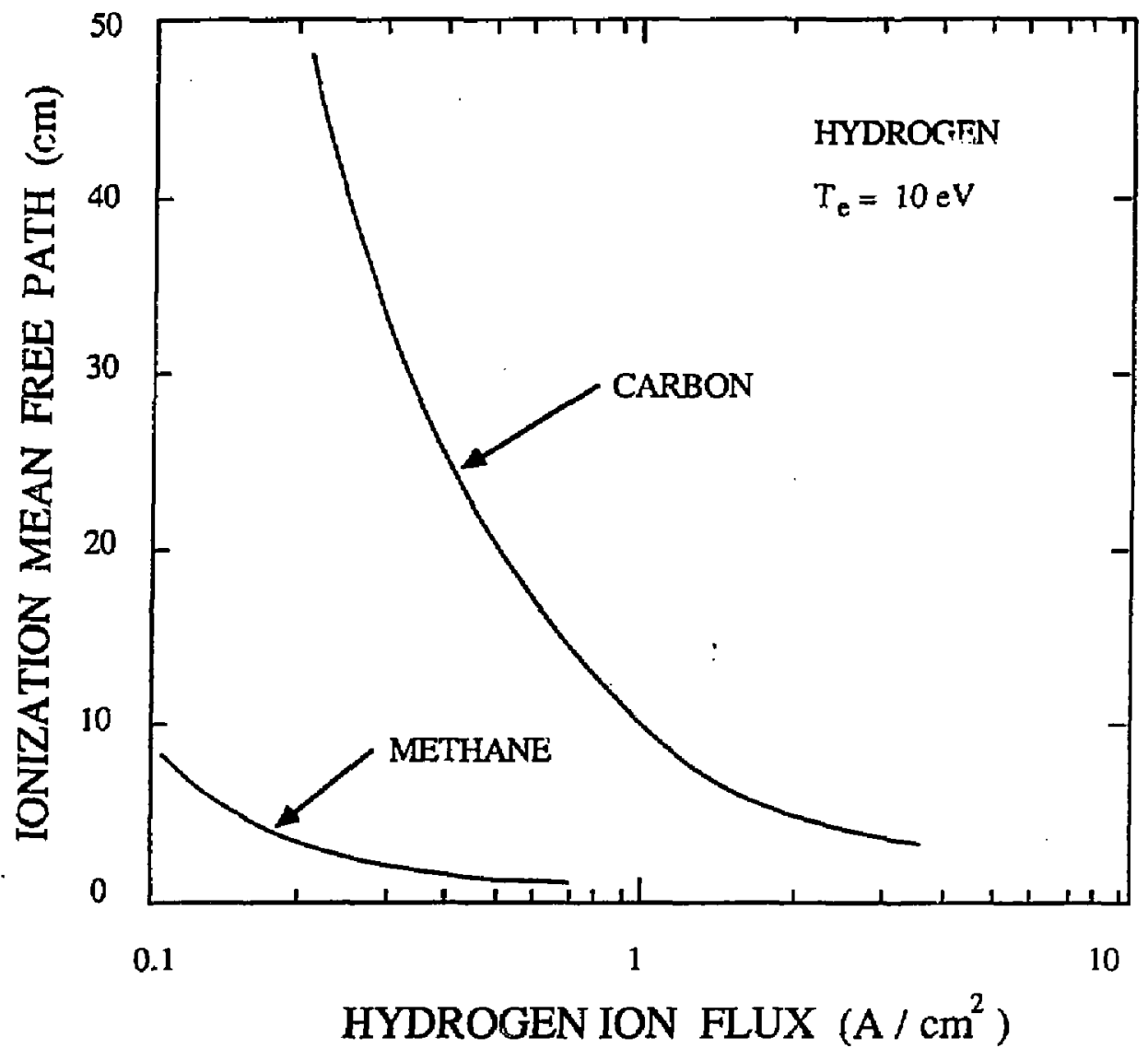

Figure 11 

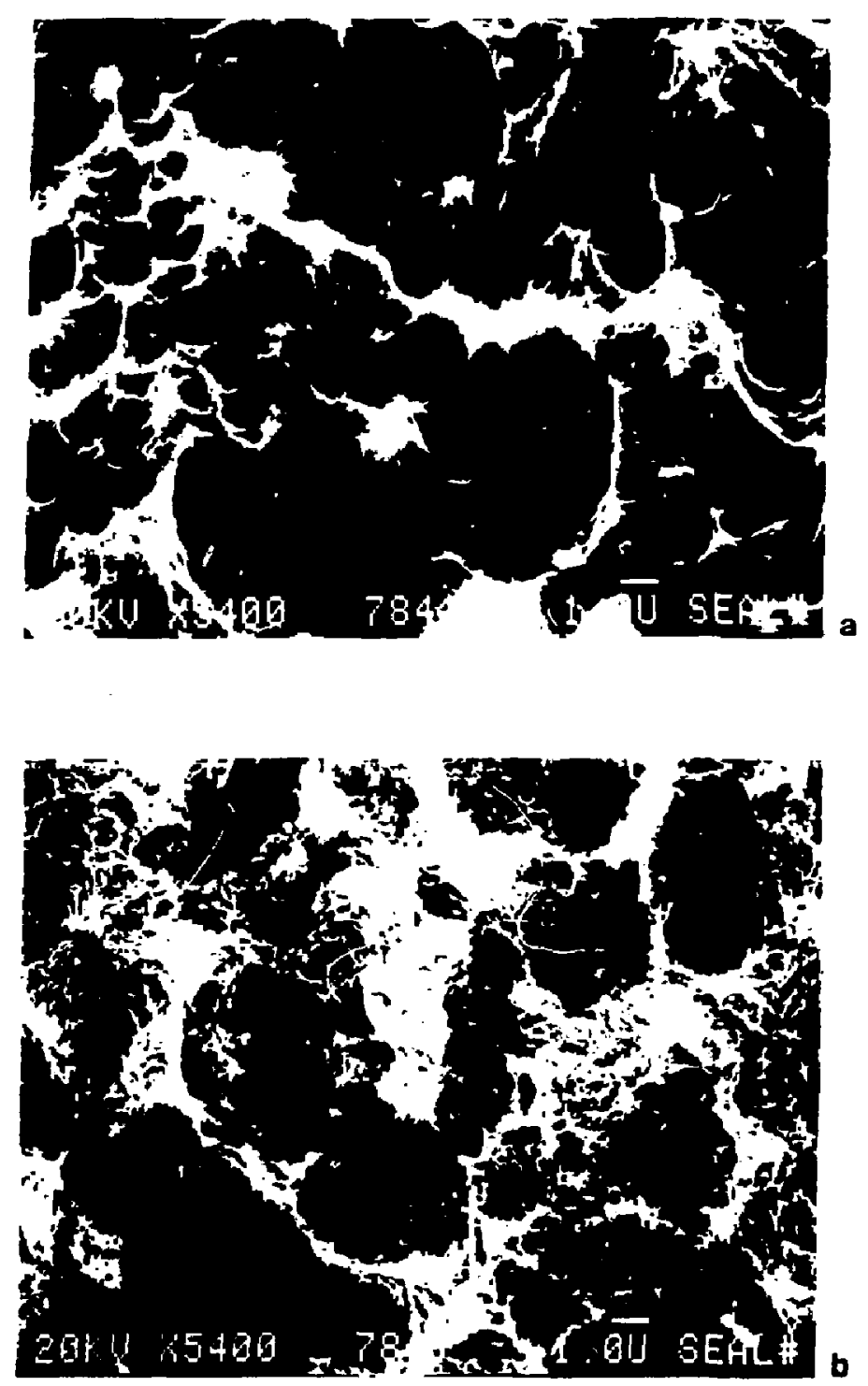